\title{
História e reflexão sobre as políticas de saúde mental no Brasil e no Rio Grande do Sul
}

\section{History and reflection on the mental health policies in Brazil and the Rio Grande do Sul}

\section{Míriam Thais Guterres Dias*}

Universidade Federal do Rio Grande do Sul - UFRGS, Porto Alegre, Rio Grande do Sul, Brasil

\begin{abstract}
RESUMO
O presente trabalho analisa a constituição da política de saúde mental no Brasil e no estado do Rio Grande do Sul, contextualizada na trajetória das políticas de saúde no Brasil, com suas conexões com o sistema econômico, político e social do país, na perspectiva teórica dialético-crítico. 0 momento histórico analisado foi entre o Império e o final do século $X X$, período de significativas transformações na modelagem das políticas sociais, decorrentes das mudanças ocorridas no papel do Estado. A análise teórica considerará os movimentos presentes nas articulações entre o campo do conhecimento e o campo econômico e político, determinado a constituir e consolidar um estado nacional e desenvolvimentista. Quadros e sínteses apresentarão os acontecimentos mais relevantes nos períodos analisados, para melhor contextualização e análise dos mesmos.
\end{abstract}

Palavras-chave: História da saúde mental, Políticas de saúde mental, Brasil, Rio Grande do Sul.

\begin{abstract}
The present work analyzes the constitution of mental health care policy in Brazil and in the state of Rio Grande do Sul. It will evaluate the trajectory of the mental health care policies in Brazil, with its connections to the country's economic, politic and social system, in theory perspective dialectical-critic. For that, it will be studied the period comprised from the Empire until the end of the 20th century, a period of significant changes in the mould of social policies, caused by modifications occurred in the role of the State. Hence, the theoretical analysis will take into account the actions presented in the articulations between the technical knowledge and the economic and politic field in order to construct and consolidate a national and developmental state. Synthesis charts will present the most relevant events occurred in the evaluated period in order to better understand and analyze them.
\end{abstract}

Keywords: History of mental health care politics, Mental health care policies, Brazil, Rio Grande do Sul. 


\section{Introdução}

A constituição da política de saúde mental no Brasil e no estado do Rio Grande do Sul, contextualizada na trajetória das políticas de saúde no Brasil, com suas conexões com o sistema econômico, político e social vigente tem relevância por possibilitar conhecimento e reflexões sempre necessários para produção e avaliação de políticas sociais. O período histórico analisado foi o discorrido entre o Império e o final do século $X X$, com suas significativas modelagens das políticas sociais decorrentes do papel do Estado brasileiro, compondo a produção de doutoramento em Serviço Social.

As políticas públicas sociais são constituídas a partir de um determinado modo de a sociedade conceber e explicar fenômenos sociais para que a ação pública se efetive com seus dispositivos legais e de gestão. A política setorial da saúde e sua especificidade de saúde mental foram gestadas no teor, ritmo e tempo característicos da formação e consolidação do Estado brasileiro ao longo do século XX, particularidades que as moldam com feições dinâmicas e contraditórias.

O interesse em analisar a política de saúde mental brasileira está no fato de que esta passou por uma revisão crítica ao modelo hegemônico existente até meados dos anos 1980. Sua perspectiva contemporânea é fruto do movimento da reforma psiquiátrica, concebida no bojo da Reforma Sanitária e instalada no contexto do debate sobre a Reforma do Estado no Brasil nos anos 1990. Entendese como reforma psiquiátrica o processo de reversão do modo manicomial e hospitalocêntrico de lidar com o fenômeno do transtorno mental e do sofrimento psíquico, com a centralidade da cidadania dos sujeitos, estes inseridos numa histórica e determinada sociedade (DIAS, 2007).

Desde então, um conjunto de reivindicações, legislações e adoção de novas modalidades de atenção em saúde mental vêm sendo implantadas, tanto pela ação de agentes sociais como pelo Estado. A processualidade dos movimentos contraditórios em diferentes estágios da vida social traduz-se na historicidade, categoria analítica central neste estudo. As mudanças nas sociedades são permanentes, sendo importante verificar os rumos que estas provocam em relação a determinados aspectos de interesse à sociedade.

$\mathrm{O}$ artigo está organizado em momentos que procuram demarcar a trajetória das políticas de saúde mental no Brasil e no Rio Grande do Sul nos contextos e eventos mais relevantes em quinze décadas, inseridas nas respectivas políticas de saúde, cujo critério foi as características do Estado brasileiro. Assim, os marcadores escolhidos foram: Do Império à República Velha; o Governo Provisório, Constitucionalista e Estado Novo; Período Desenvolvimentista, da 
Ditadura Militar e da Nova República ao final do século XX, com quadros sínteses ilustrativos dos acontecimentos mais relevantes.

\section{Do Império à República Velha}

As políticas de saúde e de saúde mental nasceram sob a égide da filantropia e da preocupação com as condições necessárias para a reprodução da força de trabalho, e não na perspectiva dos direitos e dos cuidados dignos aos indivíduos. A política social do tipo residual (PEREIRA, 2002) foi a marca do período do Império até a década 1930 no Brasil, quando a assistência à saúde da população em geral era realizada pelas instituições hospitalares vinculadas a entidades religiosas.

O modelo clássico de atenção em saúde mental foi a construção e manutenção de grandes asilos psiquiátricos que demonstraram sua incapacidade de tratar e de respeitar os direitos dos portadores de transtorno mental. Esta também foi a trajetória do Hospital Psiquiátrico São Pedro, no estado do Rio Grande do Sul, que por mais de um século centralizou o atendimento em saúde mental. O Quadro 1 apresenta uma síntese deste período.

Quadro 1 - Síntese da Trajetória das Políticas de Saúde e Saúde Mental no Brasil e no Rio Grande do Sul - Império e República Velha.

\begin{tabular}{|c|c|}
\hline ANO & ACONTECIMENTOS \\
\hline 1852 & Inauguração do Hospício Dom Pedro II, Rio de Janeiro, RJ. \\
\hline 1860 & $\begin{array}{l}\text { Casa de Saúde Doutor Eiras, primeira instituição psiquiátrica } \\
\text { privada do país, Rio de Janeiro, RJ. }\end{array}$ \\
\hline 1884 & Inauguração do Hospício São Pedro, Porto Alegre, RS. \\
\hline 1903 & $\begin{array}{l}\text { Lei Federal de Assistência aos Alienados, n 1.132, de 22/12/1903. } \\
\text { Reorganiza a assistência aos alienados. }\end{array}$ \\
\hline 1919 & Primeira Lei de proteção aos Acidentes de Trabalho. \\
\hline 1921 & $\begin{array}{l}\text { Lei Carlos Chagas, ampliação dos serviços de saúde pela ação } \\
\text { estatal. }\end{array}$ \\
\hline \multirow[t]{3}{*}{1923} & $\begin{array}{l}\text { Lei Eloy Chaves - previdência social para ferroviários e portuários, } \\
\text { através da criação das Caixas de Aposentadorias e Pensões - } \\
\text { CAPs. }\end{array}$ \\
\hline & Promulgação do Código Sanitário. \\
\hline & Criada a Liga Brasileira de Higiene Mental, no Rio de Janeiro. \\
\hline \multirow[b]{2}{*}{1924} & 10 Congresso Brasileiro de Higiene. \\
\hline & $\begin{array}{l}\text { Decreto } 3.356 \text { governo RS, intendentes municipais entre as } \\
\text { autoridades competentes para requisitarem a internação de } \\
\text { pacientes no Hospital São Pedro. }\end{array}$ \\
\hline
\end{tabular}




\begin{tabular}{|l|l|}
\hline 1926 & Hospital Psiquiátrico Espírita de Porto Alegre, privado filantrópico. \\
\hline 1929 & $\begin{array}{l}\text { Congresso de Higiene e Hospitais, na cidade de Rio Grande, RS, } \\
\text { discute a criação de Anexos Psiquiátricos nos hospitais gerais das } \\
\text { principais cidades do RS. }\end{array}$ \\
\hline
\end{tabular}

Fontes: OMS, 1955; FARIA, 1981; FEE, 1983; CERQUEIRA, 1984; COSTA, 1986; COSTA, 1989; DELGADO, 1994; GUIMARÃES e TAVARES, 1994; PAULIN; TURATO, 2004; HOCHMAN, 2005; FIOCRUZ, 2005; RAMOS, GEREMIAS, 2006.

A institucionalização do tratamento dos doentes mentais foi uma das obrigações das Santas Casas de Misericórdia, decorrente do caráter de assistência social destas organizações. A Santa Casa de Porto Alegre iniciou suas atividades em 1826, com o recolhimento dos doentes mentais da então Província de São Pedro, denunciando ao governo seus sucessivos prejuízos financeiros e desgaste na sua imagem filantrópica, ao não conseguir prestar um serviço adequado aos pacientes (WADI, 2002).

A mobilização realizada pela Santa Casa provocou o governo a assumir diretamente uma ação de atendimento em saúde mental, com a criação do Hospício São Pedro que iniciou suas atividades em 1884, renomeado como Hospital Psiquiátrico São Pedro em 1961.

No cenário de eclosão da Primeira Guerra Mundial (1914-1918) e da necessidade de redefinir a composição da força de trabalho em decorrência do encerramento do ciclo do trabalho escravo, base da mão de obra da época, fez-se necessária a adoção de estratégias para a reprodução das condições de vida das classes trabalhadoras, que emergiam com a instalação do modo de produção capitalista nos primórdios de sua fase industrial. Estas classes irão demandar as primeiras ações estatais no setor de saúde brasileiro (COSTA, 1986), a partir de um conjunto de medidas com o apoio do círculo intelectual médico-sanitário, para a preservação da saúde da força de trabalho e no controle e erradicação de um conjunto de doenças transmissíveis que subjugava a saúde da população.

A principal ênfase na saúde pública naquele momento era 0 saneamento, motivo que levou o círculo médico-sanitário a defender a inclusão da carreira médica neste campo. Esta legitimidade pode ser medida pela criação dos Congressos Brasileiros de Higiene, no ano de 1924 (HOCHMAN, 2005), que por várias décadas influenciaram o pensamento técnico e político na saúde pública brasileira.

O pensamento sanitarista foi constituído na concepção higienista, assentado num conjunto de práticas sanitárias para erradicar doenças transmissíveis que afetam as condições de saúde. Articulado a ele, esteve presente a concepção da eugenia, referente ao "estudo dos fatores socialmente controláveis que podem elevar ou rebaixar as 
qualidades raciais das gerações futuras, tanto física como mentalmente" (COSTA, 1989).

A eugenia se constituiu em um movimento intelectual que correspondeu a vários interesses, como sanear os aglomerados urbanos e rurais e imprimir novos comportamentos sociais para debelar os efeitos da miscigenação racial, considerada um risco social pela elite conservadora (STANCIK, 2004). Deste modo, houve a aproximação histórica entre a eugenia e o higienismo na conformação da saúde pública brasileira, influenciando sua expressão na saúde mental de modo hegemônico, representado pela Liga Brasileira de Higiene Mental, fundada em 1923, bem como na criação de hospitais e colônias-agrícolas públicas para pessoas com transtornos mentais, tuberculose ou hanseníase.

Os médicos psiquiatras da época passaram a defender a prevenção eugênica como o instrumento mais rápido e eficaz para sanar a situação de degradação moral e social causada por "vícios, ociosidade e miscigenação racial do povo brasileiro" (COSTA, 1989). A categoria assistencialismo também esteve presente neste processo de institucionalização da saúde mental como política de governo, marcando até a atualidade a função social dos hospitais psiquiátricos. Até meados do século XIX, "o trabalho e as instituições de saúde repousavam em três pilares: a medicina liberal, as medidas coletivas de prevenção e higiene e o assistencialismo" (MÉDICI, 1995).

No Rio Grande do Sul, o ingresso de pacientes no Hospício São Pedro atendia também as necessidades públicas, pois os Intendentes Municipais foram autorizados a requisitarem internação psiquiátrica, através de ato do executivo estadual. É interessante constatar que já naquela época surgia a proposta de incluir hospitais gerais no atendimento em saúde mental, pois no Congresso de Higiene e Hospitais da cidade de Rio Grande, em 1929, foi proposta a criação de anexos psiquiátricos nos hospitais das principais cidades do Estado, como forma de reduzir o número de internos no São Pedro (GODOY, 1955).

Ao fim da República Velha (1889-1930), o Estado impulsionou a criação de mecanismos para responder as demandas do mundo do trabalho, tais como: legislação sobre acidentes de trabalho; ampliação dos serviços de saúde pela ação estatal; promulgação do primeiro Código Sanitário; e instalação da previdência social privada, que originaram o sistema de previdência social e da medicina previdenciária pública no país.

O período histórico subsequente terá a marca da premência do desenvolvimento industrial numa conformação política de ampliação do poder central federal que orientará os estados na adoção das políticas econômicas e sociais. Novos ordenamentos na organização social erigidos com a Revolução de 1930 são realizados, para 
responder às demandas sociais e garantir uma unidade nacional no projeto de industrialização.

\section{O Governo Provisório, Constitucionalista e Estado Novo}

O cenário internacional de crise econômica no final dos anos 1920 do século XX repercutiu no Brasil e influenciou na alteração do modelo econômico, até então sob a hegemonia do setor agroexportador cafeeiro. Desencadeou uma desarticulação das forças políticas e econômicas vigentes, criando as condições para o Estado brasileiro assumir a centralidade na condução do processo produtivo e político (FLEURY, 1994).

A Revolução de 1930 inicia então um novo ciclo econômico e reconfigura o papel do Estado brasileiro, demarcado com a ascensão de Getúlio Vargas como presidente em três momentos particulares: Governo Provisório (1930-1934), Constitucionalista (1934-1937) e Estado Novo (1937-1945). No âmbito econômico, foi o período de passagem para a economia urbano-industrial e consequente declínio do poder oligárquico, hegemônico na República Velha.

O Estado se orienta pela modernização do estilo de vida da população, e adota a política de atender as massas populares como fonte de legitimação e de poder, bem como o estilo intervencionista na economia e nas políticas sociais (SAES, 1999; PEREIRA, 2002). Uma síntese deste período está no Quadro 2.

Quadro 2 - Síntese da Trajetória das Políticas de Saúde e Saúde Mental no Brasil e no Rio Grande do Sul - Governo Provisório, Constitucionalista e Estado Novo (1930-1945)

\begin{tabular}{|c|c|}
\hline ANO & ACONTECIMENTOS \\
\hline 1930 & Criação do Ministério da Educação e Saúde Pública. \\
\hline 1931 & Clínica Olivé Leite, hospital psiquiátrico privado em Pelotas, RS. \\
\hline \multirow[t]{2}{*}{1933} & $\begin{array}{l}\text { Criação dos Institutos de Aposentadorias e Pensões - IAP`s, que } \\
\text { institui a política de assistência médica previdenciária, destinada a } \\
\text { grupos de trabalhadores urbanos mais organizados. }\end{array}$ \\
\hline & Clínica São José, hospital psiquiátrico privado em Porto Alegre, RS. \\
\hline 1934 & $\begin{array}{l}\text { Lei no. 24.559, que dispõe sobre a Assistência e Proteção à Pessoa e } \\
\text { aos Bens dos Psicopatas. }\end{array}$ \\
\hline 1935 & Secretaria de Educação e Saúde Pública , no RS. \\
\hline 1937 & $\begin{array}{l}\text { Reforma do Ministério, que passa a se denominar Ministério da } \\
\text { Educação e Saúde. }\end{array}$ \\
\hline
\end{tabular}




\begin{tabular}{|l|l|}
\hline & Lei criando as Conferências Nacionais de Saúde e de Educação. \\
\hline 1941 & $\begin{array}{l}\text { Criação dos serviços nacionais de saúde: Doenças Mentais, } \\
\text { Organização Sanitária, Organização Hospitalar, Lepra, Tuberculose, } \\
\text { Febre Amarela, Peste, Fiscalização da Medicina, Propaganda e } \\
\text { Educação Sanitária, do Câncer e da Criança. }\end{array}$ \\
\hline 1942 & $\begin{array}{l}\text { Lei obrigando a notificação de doenças profissionais provocadas por } \\
\text { substâncias tóxicas, utilizadas nas indústrias e por condições } \\
\text { ambientais inadequadas à saúde. }\end{array}$ \\
\hline
\end{tabular}

Fontes: OMS, 1955; FEE, 1983; FARIA, 1981; CERQUEIRA, 1984; COSTA, 1986; COSTA, 1989; DELGADO, 1994; GUIMARÃES e TAVARES, 1994; PEREIRA, 2002; HOCHMAN, 2005; FIOCRUZ, 2005; RAMOS, GEREMIAS, 2006.

A regulamentação de medidas de proteção social é do "tipo meritocrático-particularista, com fortes marcas corporativas e clientelistas na consagração de privilégios e na concessão de benefícios" (DRAIBE, 1993), gerando as condições favoráveis para o fortalecimento do Estado através de um aparato governamental unificado em todo o território nacional.

A criação do Ministério da Educação e Saúde Pública reflete a estratégia campanhista vigente na época, com o mecanismo da prevenção sendo privilegiado para combater doenças, e para tanto, é imprescindível a educação. Concomitante, o governo fortaleceu a política de saúde ancorada na assistência médica previdenciária, destinada a grupos de trabalhadores urbanos mais organizados, através da criação dos Institutos de Aposentadorias e Pensões (IAPs) via a unificação das CAPs, e no solo gaúcho, a Secretaria de Educação e Saúde Pública em 1935.

A criação dos IAPs mantêm a prestação da assistência médica dependente da contribuição dos trabalhadores, confirmando a concepção predominante de que a saúde individual não era da competência da área de saúde pública, como expressa Gustavo Capanema, sanitarista e ministro da saúde e educação por um longo período: "O caso individual só interessa à saúde pública se puder afetar a coletividade, se for capaz de pôr a coletividade em perigo" (HOCHMAN, 2005). A responsabilidade da saúde pública estava diretamente vinculada à função estatal para evitar riscos à coletividade.

Nesta lógica está o fundamento da aprovação do Decreto sobre a assistência e proteção à pessoa e aos bens dos psicopatas. O artigo 1.0 define que esta assistência pretende "concorrer para a realização da higiene em geral e da profilaxia das psicopatias em especial" (DELGADO, 1992), expressando e materializando o escopo da higiene mental. No artigo $4 . .^{\circ}$ está a definição dos estabelecimentos 
psiquiátricos, e entre estes, os de assistência social relacionado ao fenômeno do transtorno mental num país marcado pela desigualdade social, e com a presença significativa de organizações privadas filantrópicas a quem a sociedade delegou a tarefa de isolar e segregar a pobreza.

No Rio Grande do Sul, o diretor do hospital São Pedro, Jacintho Godoy, realiza um conjunto de obras na instituição, instala serviços ambulatoriais e cria condições para carreiras profissionais se desenvolverem: médico psiquiatra, Escola de Enfermagem e o Serviço de Assistência Social. O fenômeno da superlotação era a marca da instituição, que cumpria sua função social de depositário estadual de todo tipo de indesejados e pobres da sociedade. A capacidade do hospital era de 477 pacientes, mas no período chegou a abrigar 1.800 pessoas.

\section{Período Desenvolvimentista}

O desfecho da Segunda Guerra Mundial marca no Brasil o início do período desenvolvimentista (1946-1964), "projeto de superação do subdesenvolvimento através da industrialização integral, por meio de planejamento e decidido apoio estatal" (BIELSCHOWSKI, 2004, p. 33). O setor saúde é considerado estratégico para o desenvolvimento econômico, sendo um dos quatro pilares do Plano SALTE, saúde, alimentos, transporte e energia, precondição ao aumento da produção e da riqueza social (FEE, 1983). Confirmando, assim, a concepção de saúde presente na gênese de sua constituição de política pública no Brasil, como fundamental na reprodução das condições de vida das classes trabalhadoras e um setor considerado rentável pelos agentes econômicos. Uma síntese deste período está no Quadro 3.

Quadro 3 - Síntese da Trajetória das Políticas de Saúde e Saúde Mental no Brasil e no Rio Grande do Sul - Período Desenvolvimentista $(1945$ - 1964)

\begin{tabular}{|l|l|}
\hline ANO & ACONTECIMENTOS \\
\hline 1946 & $\begin{array}{l}\text { Decreto Lei no. 8.550 autorizou o Serviço Nacional de Doenças } \\
\text { Mentais a realizar convênios com governos estaduais para a } \\
\text { construção de hospitais psiquiátricos. }\end{array}$ \\
\hline 1948 & Sanatório Psiquiátrico Espírita, privado conveniado em Pelotas, RS. \\
\hline 1949 & $\begin{array}{l}\text { Hospital Psiquiátrico Maria Vicença F. Lopes, privado conveniado } \\
\text { em Rio Grande, RS. }\end{array}$ \\
\hline 1950 & $\begin{array}{l}\text { Plano SALTE - Saúde, Alimentos, Transportes e Energia. Lei } \\
\text { Federal no. 196, de 1948, aprovado através da Lei no. 1.102. }\end{array}$ \\
\hline 1953 & Criação do Ministério da Saúde. \\
\hline
\end{tabular}




\begin{tabular}{|c|c|}
\hline \multirow[t]{2}{*}{1954} & $\begin{array}{l}\text { Criação do Laboratório Central de } \text { Controle de Drogas e } \\
\text { Medicamentos, pelo incremento da indústria farmacêutica: } \\
\text { antibióticos e psicofármacos. }\end{array}$ \\
\hline & $\begin{array}{l}\text { OMS - Legislação em Matéria de Assistência Psiquiátrica - } \\
\text { Comissão de Especialistas em Saúde Mental. }\end{array}$ \\
\hline \multirow[t]{2}{*}{1960} & Lei Orgânica da Previdência Social. \\
\hline & $\begin{array}{l}\text { Clínica Pinel, hospital psiquiátrico privado conveniado, Porto } \\
\text { Alegre, RS. }\end{array}$ \\
\hline 1961 & Decreto n०. 49.974 institui o Código Nacional de Saúde. \\
\hline 1963 & $\begin{array}{l}\text { Decreto no. } 52.464 \text { - Normas Técnicas Especiais para a Orientação, } \\
\text { Organização, Funcionamento e Fiscalização das Instituições de } \\
\text { Assistência Médico-Social, sob a responsabilidade do Ministério da } \\
\text { Saúde. }\end{array}$ \\
\hline
\end{tabular}

Fontes: COSTA, 1989; GUIMARÃES e TAVARES, 1994; PAULIN e TURATO, 2004; HOCHMAN, 2005.

Neste período, os Estados Unidos da América passaram a exercer influência hegemônica sobre o mundo capitalista, possibilitando a difusão e expansão do seu modelo assistencial hospitalocêntrico de alta tecnologia e da prática especializada (ALMEIDA, 1997). Esta orientação influenciou a saúde mental no Brasil, com o governo promulgando o Decreto Lei $n^{\circ}$. 8.550 que estimula a construção de hospitais psiquiátricos pelos governos estaduais, na óptica de consolidar "[...] a política macro-hospitalar pública como o principal instrumento de intervenção sobre a doença mental" (PAULIN; TURATO, 2004).

Esta política aumentou o número de hospitais e da população institucionalizada: "em 1950 existiam 0,41 internados por 1.000 habitantes; 0,82 em 1970. Enquanto a população geral aumentou $82 \%$ em 20 anos, a população do hospital psiquiátrico aumentou 213\%, apesar do advento dos psicotrópicos" (CERQUEIRA, 1984). Este quadro de valorização da hospitalização psiquiátrica como eixo da política pública de saúde mental será uma tônica no Brasil pelas décadas subsequentes.

A urbanização, fenômeno que na América Latina foi consequente da mudança acelerada da base produtiva de agrário-exportadora para urbano-industrial, também colaborou para o aumento da população nos hospitais psiquiátricos. Aos grupos populacionais que não conseguiram ingressar neste novo padrão de produção, um dos lugares destinados foram os hospitais psiquiátricos. Em 1950, existiam 24.234 leitos psiquiátricos, passando para 34.550 leitos em 1955 (ALVES et al, 1992; COSTA, 2002).

A saúde mental no Rio Grande do Sul teve uma expressiva visibilidade, tanto por ações realizadas no Hospital Psiquiátrico São Pedro, quanto na política setorial. A higiene mental e a assistência 
psiquiátrica mereceram capítulo especial no Código Estadual de Saúde (1962), pois as psicoses passaram a ter notificação obrigatória. Vários convênios foram firmados entre o Ministério da Saúde e a Secretaria Estadual visando o incremento de construção e reformas em hospitais psiquiátricos, e uma política de expansão destes estabelecimentos, com a construção de três hospitais psiquiátricos privados.

Neste período houve uma proliferação de referenciais teóricos incorporados no HPSP, como a psicanálise, a ambientoterapia e a formação multiprofissional na forma de residência, assim como o trabalho e a expressão artística como propostas terapêuticas (DIAS, 2007).

No âmbito internacional, a Organização Mundial da Saúde (OMS, 1955) analisou as legislações em saúde mental em diversos países, constatando a ênfase nos aspectos jurídicos em detrimento dos cuidados em saúde. Entre outras diretrizes, foi estabelecida a necessidade de serem criadas normas para orientação técnica do atendimento hospitalar psiquiátrico, referendando o modelo de política de saúde mental centrado nesta instituição.

A reorganização da previdência social pela promulgação da Lei Orgânica da Previdência Social dinamizou este modelo, pois a assistência médica previdenciária passa a ser uma resposta do Estado à classe assalariada, que perdia capacidade de consumo devido a deteriorização nos valores do salário mínimo na época. 0 entendimento é de que a perda salarial se compensa pela assistência médica, pois "as sequelas poderão ser tratadas medicamente, as epidemias combatidas, a tuberculose e o desequilíbrio emocional tratados" (IAMAMOTO; CARVALHO, 1988, p. 248).

As primeiras críticas aos hospitais psiquiátricos surgem no período pós-Segunda Guerra Mundial, a partir da experiência de médicos e enfermeiros que foram prisioneiros dos campos de concentração nazistas. Inicia-se, assim, um questionamento sobre a participação destes profissionais em instituições psiquiátricas, que se baseiam em discriminações tão desumanas como as que eles haviam padecido (TUÑON; ABUDARA, 1988).

O setor saúde segue permeado pela disputa por legitimidade entre os dois blocos existentes: a saúde pública, com seu modelo campanhista, e a atenção médica previdenciária, de cunho curativista e privado. Um amplo debate nacional sobre o papel do Estado na implantação de um efetivo sistema de saúde se realiza, com sua grande expressão na $3^{a}$ Conferência Nacional de Saúde (1963), quando o Ministério da Saúde propôs a criação de um Plano Nacional de Saúde e a Municipalização dos serviços de saúde no Brasil. Contudo, esta possibilidade de significativa mudança no modo de atenção à saúde no país vai ser postergada por algumas décadas. 


\section{Período da Ditadura militar}

Como consequência do Golpe Militar de 1964 e instalação da ditadura no Brasil, a ausência de debate e de fortalecimento das vontades políticas nos níveis regionais e locais, aliada à implantação de reformas institucionais, afetou a saúde pública e a medicina previdenciária existente. Uma síntese deste período está presente Quadro 4.

Quadro 4 - Síntese da Trajetória das Políticas de Saúde e Saúde Mental no Brasil e no Rio Grande do Sul - Período da Ditadura Militar $(1964-1985)$

\begin{tabular}{|c|c|}
\hline ANO & ACONTECIMENTOS \\
\hline 1964 & $\begin{array}{l}\text { Decreto } \mathrm{n}^{\circ} .16 .722 \text {, para a criação de Ambulatórios em Saúde } \\
\text { Mental em } 18 \text { municípios do estado do RS. }\end{array}$ \\
\hline 1966 & $\begin{array}{l}\text { Instituto Nacional de Previdência Social - INPS, substituindo os } \\
\text { antigos Institutos de Aposentadoria e Pensões por categorias de } \\
\text { trabalhadores. }\end{array}$ \\
\hline 1967 & $\begin{array}{l}\text { Campanha Nacional de Saúde Mental - Ministério da Saúde, } \\
\text { Decreto nº. } 60.252 \text {. }\end{array}$ \\
\hline \multirow[t]{3}{*}{1972} & $\begin{array}{l}\text { OPAS e Ministério da Saúde assinam "Acordo para a execução de } \\
\text { um Programa de Saúde Mental no Brasil". }\end{array}$ \\
\hline & $\begin{array}{l}\text { Lei } n^{\circ} .6 .503 \text {, Estado do RS - Código Sanitário - dispõe sobre a } \\
\text { promoção, proteção e recuperação da Saúde Pública. Título III, da } \\
\text { Promoção e Recuperação da Saúde, consta o Capítulo II, da } \\
\text { Assistência Social e Psiquiátrica. }\end{array}$ \\
\hline & $\begin{array}{l}\text { Clínica Psiquiátrica Prof. Paulo Guedes, em Caxias do Sul, RS. } \\
\text { Privada e contratada. }\end{array}$ \\
\hline \multirow{3}{*}{1973} & $\begin{array}{l}\text { Manual de Serviço, valorizando a psiquiatria de comunidade para } \\
\text { a assistência extra-hospitalar. Resolução no. } 304 \text { do INPS. }\end{array}$ \\
\hline & $\begin{array}{l}\text { Programa de Setorização no HPSP e Programa de Interiorização } \\
\text { da saúde mental no RS. Pela primeira vez o Programa de Saúde } \\
\text { Mental é incluído entre as prioridades da Secretaria Estadual da } \\
\text { Saúde do RS. }\end{array}$ \\
\hline & $\begin{array}{l}\text { Criação do Ambulatório Central de Psiquiatria (Central de } \\
\text { Psiquiatria), em Porto Alegre, RS. Atendimento estadual em e } \\
\text { emergência - triagem - ambulatório. }\end{array}$ \\
\hline \multirow{3}{*}{1974} & Criação do Ministério da Previdência e Assistência Social \\
\hline & $\begin{array}{l}\text { Ministério da Saúde estabelece o sistema hierarquizado e } \\
\text { regionalizado de saúde mental. Portaria } \mathrm{n}^{\circ} .32 \text {. }\end{array}$ \\
\hline & $\begin{array}{l}\text { OMS - Comitê de especialistas em saúde mental, em outubro - } \\
\text { Genebra. }\end{array}$ \\
\hline & $\begin{array}{l}\text { Lei } 6.229 \text { cria o Sistema Nacional de Saúde, estabelecendo os } \\
\text { campos institucionais da saúde coletiva e da saúde individual. }\end{array}$ \\
\hline
\end{tabular}




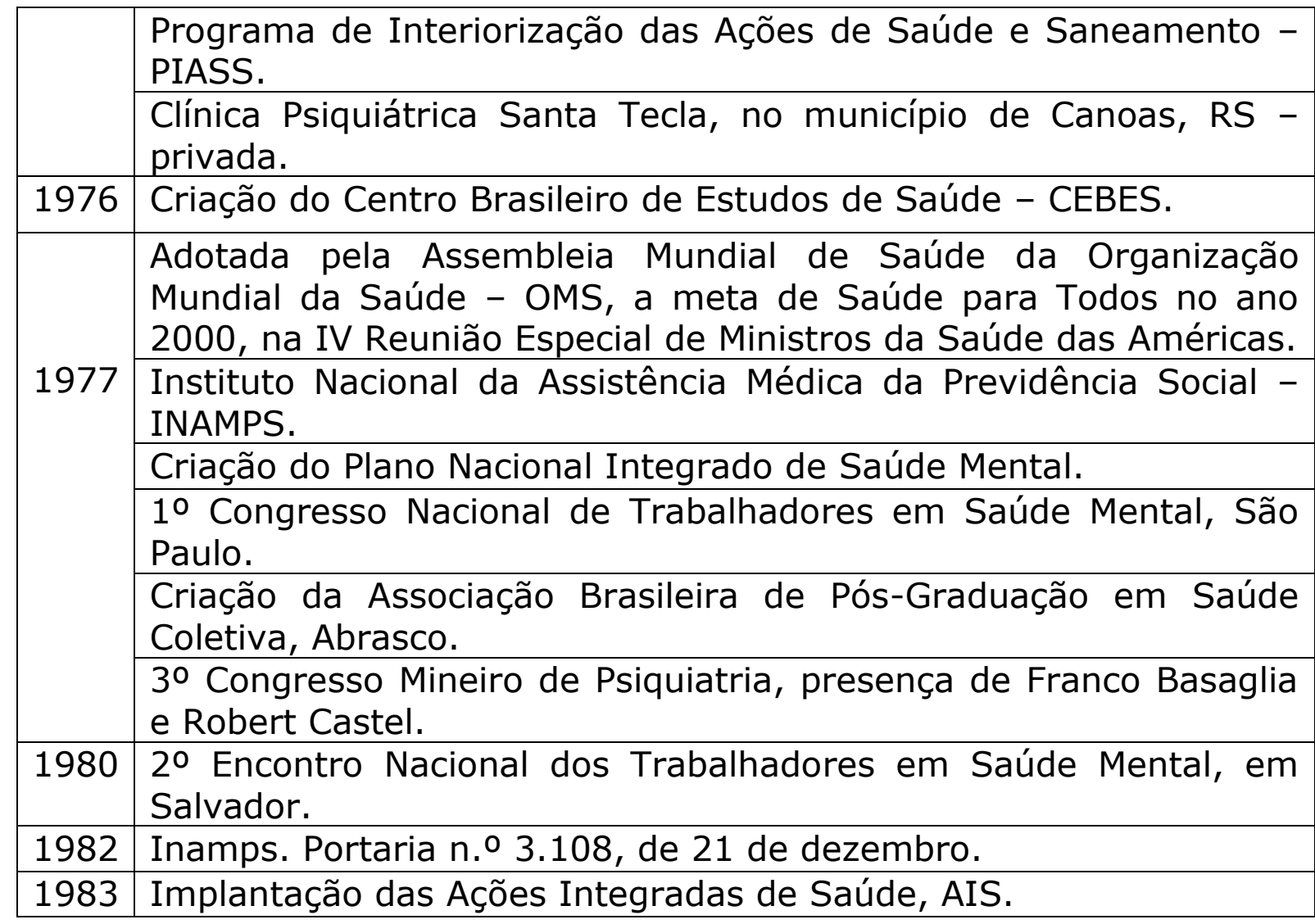

Fontes: FARIA, 1981; FEE, 1983; COSTA, 1986; COSTA, 1989; DELGADO, 1994; GUIMARÃES; TAVARES, 1994; AMARANTE, 1995a; HOCHMAN, 2005; FIOCRUZ, 2005; RAMOS, GEREMIAS, 2006.

O Estado reorganiza sua estrutura de proteção social, intensificando sua centralização e sua função de busca de coesão social através de oferta de serviços de saúde à população. A criação do Instituto Nacional de Previdência Social (INPS), em 1966, unificou os institutos existentes e excluiu os trabalhadores da participação direta na sua administração.

O Ministério da Assistência e Previdência Social é criado, com atuação voltada principalmente para 0 atendimento médico-assistencial individualizada, visando organizar e ampliar os benefícios sociais com a incorporação de segmentos populacionais à previdência social. Possibilitou o crescimento quantitativo da oferta de serviços e da instalação de unidades assistenciais de saúde com o financiamento do fundo previdenciário.

Destaca-se também a criação do INAMPS com sede em cada estado brasileiro, inviabilizando a condução descentralizada de políticas sociais nas esferas estaduais de governo (NORONHA; LEVCOVITZ, 1994). Estas iniciativas incrementaram a privatização no setor da saúde, tendência histórica na realidade sanitária brasileira.

As Ações Integradas de Saúde implantadas foram resultantes do ordenamento na política de saúde, cujos graus de centralização e 
crise na capacidade de oferta de serviços, visaram alcançar níveis de articulação institucional que viabilizassem ações mais eficientes e eficazes, e produziram "um deslocamento relativo de recursos financeiros da Previdência para o setor público prestador de serviços de saúde e promoveram uma integração das ações setoriais" (MERHY; QUEIROZ, 1993, p. 6).

Na política de saúde mental destaca-se o estímulo da política pública para a criação e organização de serviços ambulatoriais. No estado gaúcho o Decreto no. 16.722 criam Ambulatórios em Saúde Mental em 18 municípios, seguindo uma lógica de regionalização e densidade demográfica (RIO GRANDE DO SUL, 1964). Esta iniciativa estimulou a criação de um conjunto de ambulatórios no estado, tanto no âmbito estatal quanto no privado, que por muito tempo se constituíram como um modo de atendimento associado ao tratamento hospitalar.

No âmbito federal, é promulgado o Decreto no. 60.252 que cria a Campanha Nacional de Saúde Mental no âmbito do Ministério da Saúde. As suas finalidades e objetivos estão fundamentados nas concepções campanhistas e da higiene mental, visando resolver o déficit de hospitais psiquiátricos, apontando a ampliação e distribuição de ambulatórios de saúde mental no país, com o fim de "diminuir a necessidade de internação e assegurar a assistência terapêutica sem afastar pacientes de seu ambiente social e familiar" (BRASIL, 1968).

Durante o governo Geisel (1974 a 1979), a coalizão política do regime militar passou por uma crise econômica e de legitimidade, a primeira gerada pela desestabilização no mercado internacional do petróleo em 1973, que colaborou para o fim do período de milagre econômico brasileiro, levando ao aumento da dívida externa para custear a ampliação das importações.

O Programa de Interiorização das Ações de Saúde e Saneamento foi proposto, inspirado nas recomendações da Conferência de Alma-Ata, de que os cuidados primários de saúde integrem os sistemas de saúde dos países. Esta ação propiciou o incremento da oferta de serviços ambulatoriais básicos à população excluída do acesso a equipamentos sociais (NORONHA; LEVCOVITZ, 1994) como uma forma também de contrabalançar o grau de privatização da assistência médica expandida pela criação do Instituto Nacional de Assistência Médica da Previdência Social (INAMPS). O Plano Integrado de Saúde Mental (1978) foi estabelecido, prevendo a formação das primeiras equipes multiprofissionais de saúde mental nas coordenações estaduais de saúde, e a formação de médicos generalistas para atender ao público da saúde mental.

O efeito no estado do Rio Grande do Sul foi a realização do programa de setorização no Hospital Psiquiátrico São Pedro (HPSP), em 1973, quando os seus internos foram agrupados conforme sua região no estado, substituindo o critério adotado até então de distribuição dos 
pacientes em unidades de atendimento por diagnóstico psiquiátrico. O objetivo destas ações foi reduzir o número de internos no hospital, integrando as ações das equipes de saúde das regionais da Secretaria da Saúde com as das unidades de internação do HPSP, de modo a facilitar a localização dos familiares e/ou responsáveis pelos pacientes institucionalizados e propiciar o retorno destes na ocasião de alta (DIAS, 2007).

O programa de setorização no HPSP foi resultado concreto de uma iniciativa de organização estatal da política de saúde mental na época, pois pela primeira vez foi formada uma instância responsável pelo planejamento e gestão das ações na área: a Equipe Central de Saúde Mental na Secretaria de Saúde criada em 1972. Esta dirigiu um conjunto de ações na condução de mudanças requeridas, considerando que o programa de saúde mental foi incluído entre as prioridades de governo na área da saúde (FARIA, 1981).

Pode-se considerar que o programa de setorização foi um processo de desospitalização no HPSP, pois sua realização associada à qualificação de profissionais na lógica da regionalização resultou na diminuição de pacientes no HPSP, passando de 5.000 a 1.915 internados no final deste período. Ou seja, houve a transferência da responsabilidade do Estado para a sociedade em "cuidar" destas pessoas, sem nenhuma política pública de suporte para tal medida.

O Código Sanitário no estado do Rio Grande do Sul, sancionado em 1972, anunciava a realização de convênios com instituições psiquiátricas privadas e o estímulo à organização de novas instituições públicas ou privadas para a assistência psiquiátrica e social as pessoas com transtorno mental e sua família. O consolidado na lei refletia o momento histórico de forte investimento no setor de saúde mental, considerando que a oferta de serviços de saúde, financiados pela previdência social, foi uma relevante estratégia de relação entre o governo militar e a sociedade. Ao longo do tempo, um conjunto de casas do tipo pensões particulares foram criadas para suprir a função social até então do HPSP.

Em 1971 já existiam no Brasil 80.000 leitos psiquiátricos no Brasil (ALVES et al., 1992; COSTA, 2002). O fenômeno da superlotação continuava no Hospital Psiquiátrico São Pedro e as características e condições de sua população institucionalizada eram as seguintes: $61,7 \%$ dos pacientes na faixa etária mais produtiva, de 25 a 55 anos de idade; $63,7 \%$ sem necessidade de internação; $73,4 \%$ sem vínculo previdenciário; $55,5 \%$ eram mulheres; $42,3 \%$ com mais de 10 anos de internação, e 39\% deles sem família localizada, ou seja, o retrato da exclusão e segregação, reforçando a função social dos hospitais psiquiátricos (DIAS, 2007).

Este cenário da política de saúde mental produziu críticas e propostas de mudanças na década posterior. "[...] o sistema socioeconômico determina as modalidades de tratamento em diferentes níveis. No 
momento brasileiro atual, a estes pacientes de nível socioeconômico baixo a sociedade só reserva a modalidade asilo" (CONTEL, 1981).

O Inamps, responsável pelo pagamento das internações, faz em 1982 um diagnóstico das internações psiquiátricas no Brasil, concluindo que estas cresceram 15\% ao ano desde a década de 1970, com indicações desnecessárias, manipulações de diagnósticos para fins de ampliação de prazos de internação e uso do expediente de dar alta seguida de imediata reinternação. A Portaria nº. 3.108 foi lançada para regular mudanças no modelo assistencial em saúde mental, calcadas nos seguintes princípios: a) ser predominantemente extrahospitalar, b) ser exercida por equipe multidisciplinar, c) incluir-se numa estratégia de atenção primária de saúde, d) utilizar recursos intermediários entre o ambulatório e a internação integral, como hospital-dia, hospital-noite, pré-internação, pensão e oficina protegidas, e) restringir a internação aos casos estritamente necessários, f) promover a implantação progressiva de pequenas unidades psiquiátricas em hospitais gerais (BRASIL, 1982).

As medidas, acima relacionadas, foram instituídas num contexto particular na história brasileira, na conjuntura de crise econômica e política do ciclo ditatorial que anunciava sinais de desgaste. $O$ governo começou a ceder no seu autoritarismo e teve início a organização de entidades sindicais, o retorno do pluripartidarismo e vitória da oposição nas eleições diretas para governadores em 1982, com grandes mobilizações de variados movimentos sociais lutando por temas relacionados às condições de vida.

A inflação marcou índices alarmantes (em 1980, 110\%, em 1983, $200 \%$ ), o analfabetismo chegou a $25 \%$ dos habitantes, e o acesso aos serviços de saúde estava prejudicado pela discriminação existente entre os segurados, cujos serviços tinham maior volume de investimento e, mesmo assim, insuficientes. Os demais eram dependentes da oferta de precários serviços estatais, com ínfimo investimento, e da filantropia, responsável principal pela oferta de serviços hospitalares (GUIMARÃES; TAVARES, 1994).

Este é um quadro sintético do último governo militar, que teve a tarefa histórica de iniciar o processo de democratização no país, com a população brasileira organizada em várias forças sociais e políticas criticando e propondo mudanças nos rumos da Nação. O movimento pelas Diretas Já e a luta por uma Constituinte Livre e Soberana demonstraram o novo cenário de participação popular sob o auspício da cidadania.

Assim, a partir da metade dos anos 1980 até a última década do século $X X$, o país viveu um importante processo de mudança no campo político, com o fim da ditadura militar e a instauração do regime democrático. Neste cenário o campo da saúde e da saúde mental iniciam uma profunda crítica e análise da sua política, iniciando debates e mobilizações que se expressarão nos 
denominados movimentos da reforma sanitária e reforma psiquiátrica, sob as lideranças do CEBES, Abrasco e trabalhadores da saúde mental, respectivamente.

\section{Período da Nova República ao final do século XX}

O período da Nova República inicia com a transição democrática, através do restabelecimento de eleições diretas em todo o território nacional e a convocação de uma nova constituição, com o fim de fundar um novo consenso político e social para o país após o fim do ciclo ditatorial. O desafio na área econômica era a contenção da inflação, e para tanto vários planos foram implementados, cujas consequências repercutem em alguns setores até os dias atuais, como se destaca no Quadro 5, síntese dos acontecimentos no período.

Quadro 5 - Síntese da Trajetória das Políticas de Saúde e Saúde Mental no Brasil e no Rio Grande do Sul no Período da Nova República ao final do século XX (1985 - 1999)

\begin{tabular}{|c|c|}
\hline ANO & ACONTECIMENTOS \\
\hline \multirow[b]{3}{*}{1986} & Congresso de Bauru, dos Trabalhadores de Saúde Mental, SP. \\
\hline & 8a Conferência Nacional de Saúde, de 17 a 21 de março. \\
\hline & $\begin{array}{l}1^{\text {a }} \text { Conferência Internacional sobre Promoção da Saúde (OMS), } \\
\text { Ottawa, Canadá. }\end{array}$ \\
\hline \multirow{3}{*}{1987} & Criação do Sistema Unificado e Descentralizado de Saúde - SUDS \\
\hline & $\begin{array}{l}1^{\text {a }} \text { Conferência Nacional de Saúde Mental, Rio de janeiro, } 25 \text { a } 28 \\
\text { de julho. }\end{array}$ \\
\hline & 10 Curso de Aperfeiçoamento em Saúde Mental, Porto Alegre, RS. \\
\hline \multirow{3}{*}{1988} & Nova Constituição Federal \\
\hline & $\begin{array}{l}\text { "Nossa Casa", São Lourenço do Sul, } 1^{0} \text { serviço de saúde mental } \\
\text { substitutivo RS. }\end{array}$ \\
\hline & $\begin{array}{l}\text { I Simpósio Internacional de Saúde Mental Comunitária - SISMEC - } \\
\text { repensando a saúde mental, em Santa Maria, RS, participantes do } \\
\text { Brasil, Uruguai e Argentina. }\end{array}$ \\
\hline \multirow[t]{2}{*}{1989} & Transferência do Inamps para o Ministério da Saúde \\
\hline & Declaração de Caracas - OPAS. \\
\hline 1990 & $\begin{array}{l}\text { I e II Encontro Nacional dos Usuários e Familiares da Luta } \\
\text { Antimanicomial, realizados em São Paulo e Rio de Janeiro. }\end{array}$ \\
\hline \multirow[t]{2}{*}{1991} & $\begin{array}{l}\text { ONU - Resolução } n^{\circ} \text {. 119. Declaração sobre A Proteção de Pessoas } \\
\text { Acometidas de Transtorno Mental e a Melhoria da Assistência à } \\
\text { Saúde Mental }\end{array}$ \\
\hline & Criação Fórum Gaúcho de Saúde Mental, RS. \\
\hline \multirow[t]{2}{*}{1992} & $\begin{array}{l}\text { 1a Conferência Estadual de Saúde Mental, de } 03 \text { a } 06 \text { de junho, } \\
\text { em Tramandaí. }\end{array}$ \\
\hline & Lei da Reforma Psiquiátrica no Rio Grande do Sul, 07 de agosto. \\
\hline
\end{tabular}




\begin{tabular}{|c|c|}
\hline & $\begin{array}{l}\text { 2a Conferência Nacional de Saúde Mental, Brasília, } 01 \text { a } 04 \text { de } \\
\text { dezembro. }\end{array}$ \\
\hline \multirow{3}{*}{1993} & I Encontro Nacional da Luta Antimanicomial, Salvador, Bahia. \\
\hline & $\begin{array}{l}\text { Carta de Direitos dos Usuários e Familiares de Serviços de Saúde } \\
\text { Mental - Produzida pelos participantes do III Encontro Nacional dos } \\
\text { Usuários e Familiares da Luta Antimanicomial, realizado em } \\
\text { Santos/SP, em Dezembro. }\end{array}$ \\
\hline & $\begin{array}{l}\text { Carta Instituinte São Pedro Cidadão - Conselho Estadual de } \\
\text { Saúde, RS }\end{array}$ \\
\hline 1995 & $\begin{array}{l}\text { II Encontro Nacional da luta Antimanicomial, Belo Horizonte, Minas } \\
\text { Gerais. }\end{array}$ \\
\hline 1996 & $\begin{array}{l}\text { IV Encontro Nacional de Usuários e Familiares do Movimento da } \\
\text { Luta Antimanicomial, abril, em Franco da Rocha, SP. }\end{array}$ \\
\hline 1997 & $\begin{array}{l}\text { III Encontro Nacional da Luta Antimanicomial, Porto Alegre, Rio } \\
\text { Grande do Sul. }\end{array}$ \\
\hline \multirow[t]{2}{*}{1999} & $\begin{array}{l}\text { V Encontro Nacional de Usuários e Familiares do Movimento da } \\
\text { Luta Antimanicomial, } 11 \text { a } 13 \text { dezembro, em Betim, MG }\end{array}$ \\
\hline & $\begin{array}{l}\text { IV Encontro Nacional da Luta Antimanicomial, em Paripueira, } \\
\text { Alagoas. }\end{array}$ \\
\hline
\end{tabular}

Fontes: RUSCHEL, PECCIN, 1990; QUINTO NETO, 1992; PIÑOS, 1993; HIRDES, KANTORSKI, 2003; FAGUNDES, 2006.

Em relação ao setor saúde, o governo anunciou a crise econômica e sua incapacidade de financiá-la, intensificando 0 debate nos movimentos sociais, nas categorias profissionais e no campo acadêmico, comprometidos com mudanças sociais. Denunciaram as condições de saúde da população e propuseram alternativas para a construção de uma nova política de saúde efetivamente democrática, tendo como componentes essenciais a descentralização, a universalização, participação da população e a unificação no setor.

A $8^{a}$ Conferência Nacional de Saúde com o tema "Democracia é Saúde" representou um dos acontecimentos mais significativos de sedimentação das propostas que vinham sendo construídas e de encaminhamento para uma legitimidade social e política na área da saúde. As diretrizes desta Conferência são resultantes da produção crítica sobre o setor saúde, onde diferentes forças sociais construíram o movimento da Reforma Sanitária, entendido como "um processo de transformação da norma legal e do aparelho institucional [...], cuja expressão material se concretiza na busca do direito universal à saúde e na criação de um sistema único de serviços sob a égide do Estado" (TEIXEIRA, 1989, p. 39).

Esta concepção foi legitimada na Constituição Federal de 1988, base para a Lei Orgânica da Saúde - Sistema Único de Saúde - SUS, na forma das Leis Federais 8.080/90 e 8.142/90. O significado inovador do movimento da reforma sanitária foi sua proposta de ruptura com a 
forma histórica de constituição da política de saúde no Brasil: centralizadora, autoritária, privativista, hospitalocêntrica, meritocrática e residual. No processo de histórico de constituição do SUS no país, um esforço relevante de mudança foi a implantação do Sistema Unificado e Descentralizado de Saúde (SUDS), cujas diretrizes estavam alicerçadas nos princípios constituídos pelo movimento da Reforma Sanitária, como universalização, integralidade, regionalização e descentralização das ações de saúde.

Estes princípios foram orientadores da política de saúde mental nesta época no estado do Rio Grande do Sul, situação possível pela composição política constituída no governo no período. A gestão teve a marca de assumir politicamente a defesa dos preceitos da reforma psiquiátrica, numa crítica ao modelo hospitalocêntrico e manicomial adotado até então. As estratégias na condução da política de saúde mental foram de redistribuição do poder, resgate da cidadania da pessoa com sofrimento psíquico e com transtorno mental, bem como socialização do saber.

No âmbito internacional, a Organização Pan-americana da Saúde (OPAS,1990), realiza uma avalição da situação da atenção em saúde mental na região, e constata frequentes desrespeitos aos direitos dos seus usuários, concluindo e recomendando que a assistência deve ser de base comunitária e não mais centrada no modelo hospitalocêntrico, orientações emanadas da Declaração de Caracas.

Estes pressupostos sobre o modo de pensar a saúde mental marcou significativamente a história do setor no estado do Rio Grande do Sul, imprimindo um debate participativo, com a estratégia principal da formação e qualificação profissional (FAGUNDES, 2006). Produziu uma articulação entre o movimento social de luta pela reforma psiquiátrica e o Conselho Estadual de Saúde, que elaboraram e aprovaram a Carta Instituinte São Pedro Cidadão, projetos para a transformação do HPSP.

A gestão do Hospital Psiquiátrico São Pedro sintonizou com o movimento pela transformação da instituição, que tornou-se pública durante a realização da VII Semana de Estudos, com o tema "Por uma Sociedade sem Manicômios", com a divulgação dos direitos das pessoas com transtorno mentais, expressivas manifestações na sociedade local, ampla repercussão pela mídia da época e adesão de forças políticas gaúchas. Esta possibilidade histórica produziu e foi produzida pelo movimento gaúcho de saúde mental, defensor da luta antimanicomial e autor da lei de reforma psiquiátrica, aprovada em 1992 no estado.

Contudo, o último decênio do século XX no Brasil vai representar um momento histórico eivado de contradições. A conquista do direito da escolha livre de seus governantes e a construção de um consenso mínimo sobre direitos sociais a serem efetivados ocorreram no contexto de ajuste econômico e de reforma das estruturas do Estado, 
implicando na retração do financiamento das políticas sociais e no agravamento das históricas desigualdades sociais.

Constata-se que o princípio da universalização está cindido, com as políticas de saúde optando pelos mais pobres para terem acesso, e assim a noção de direito pleno está desconstituída. Contudo, esta situação é resultante da histórica inserção dos interesses privados no setor, que disputam com os anseios da população em ter seus direitos sociais garantidos, realidade que a sociedade brasileira vem mediando ao longo de sua história política e econômica.

\section{Considerações Finais}

A análise realizada no período de quinze décadas revelou mudanças significativas na concepção e na gestão do sistema de saúde, com a instalação da descentralização do âmbito federal para o estadual. Pode-se dizer que foi uma época revolucionária quanto à mudança de concepção sobre a forma da atenção na saúde mental, marcando a passagem para uma nova perspectiva pautada na noção de cidadania das pessoas com transtorno mental.

Os pressupostos que fundamentaram a análise do setor saúde foram - papel do Estado na formulação das políticas públicas, estas demandadas ora pelos agentes econômicos, ora por mobilizações de atores orgânicos na sociedade. Considerou também a histórica fragmentação entre saúde coletiva e atendimento médico individualizado, assinalando seus componentes intrínsecos como o sanitarismo, o higienismo, a eugenia e a visão assistencialista, ou seja, negadora de direitos, que permanecem ainda presentes nas políticas atuais da saúde e saúde mental.

A política de saúde tem uma amplitude que extrapola o próprio setor, pois desde o seu nascimento na primeira República está no cerne dos debates e da constituição das políticas sociais desenvolvidas pelo Estado brasileiro. É considerada estratégica no desenvolvimento econômico e social do país e no âmbito mundial, evidenciado pelas diferentes formas de orientação através dos organismos multilaterais. Pode-se dizer que estas orientações marcam as políticas de saúde, como a ênfase ora na hospitalização, ora na atenção primária, com destaque na saúde mental. Estas características vão fundar e constituir as políticas de saúde e saúde mental no Brasil, determinando suas formas no século vinte e um, quando os processos de reforma do Estado se consolidam.

Desafios relevantes existem para a efetiva realização da reforma psiquiátrica no país, pois, pela natureza contraditória dos processos históricos, já estão incorporados um conjunto de dispositivos legais como a Lei de Reforma Psiquiátrica do Rio Grande do Sul (1992) e a Lei Federal de Saúde Mental (2001) no mesmo tempo de ajuste 
estrutural, retração do Estado nos seus deveres constitucionais, e ampliação da privatização das políticas sociais. Mas, esta realidade coexiste com forças sociais dispostas a produzir meios e espaços para avanços possíveis.

\section{Referências}

ALMEIDA, C. Crise Econômica, Crise do Welfare State e Reforma Sanitária. In: GERSCHMAN, S; VIANNA, M. L. W. (Org.). A Miragem da pós-modernidade: democracia e políticas sociais no contexto da globalização. Rio de Janeiro: Fiocruz, 1997.

ALVES, D. S. N. ; SEIDI, E. M. F. ; SCHECHTMAN, A. ;SILVA, R. C. et al. Elementos para uma Análise da Assistência em Saúde Mental no Brasil. In: CONFERÊNCIA NACIONAL DE SAÚDE MENTAL, 2., 1992, Brasília. Anais... Brasília, DF: Ministério da Saúde, 1992. p. 46-59.

BIELSCHOWSKI, R. Pensamento econômico brasileiro: o ciclo ideológico do desenvolvimentismo. 5 . ed. Rio de Janeiro: Contraponto, 2004.

BRASIL. MINISTÉRIO DA SAÚDE. Decreto n. ${ }^{0}$ 60.252, de 21 de fevereiro de 1968. Institui a Campanha Nacional de Saúde Mental. In: Diário oficial da união, Poder Executivo, Brasília, DF, 23 fev. 1967. Seção 1, p. 2217.

- Ministério da Previdência e Assistência Social. INPS.

Portaria n.o 3.108, de 21 de dezembro de 1982. Brasília, DF, 1982.

CERQUEIRA, L. Psiquiatria social: problemas brasileiros de saúde mental. São Paulo: Atheneu, 1984.

CONTEL, J. O. B. Hospital Psiquiátrico Tradicional: uma aproximação aos diagnósticos da situação. Revista de Psiquiatria do Rio Grande do Sul, Porto Alegre, v. 3, n. 3, p. 185-189, 1981.

COSTA, N. do R. Lutas urbanas e controle sanitário: origens das políticas de saúde no Brasil. 2. ed. Petrópolis: Vozes; Rio de Janeiro: Abrasco, 1986.

COSTA, J. F. História da psiquiatria no Brasil. Rio de Janeiro: Xenon, 1989.

COSTA, A. C. F. Direito, Saúde mental e reforma psiquiátrica. Brasília: NESP / CEAM UNB. Brasília, Material de formação de sanitarista para Promotores de Justiça, 2002.

DELGADO, P. G. G. As razões da tutela: psiquiatria, justiça e cidadania do louco no Brasil. Rio de Janeiro: Te Corá, 1992.

DIAS, M. T. G. A reforma psiquiátrica brasileira e os direitos dos portadores de transtorno mental: uma análise a partir do serviço residencial terapêutico Morada São Pedro. 2007. 292f. Tese (Doutorado em Serviço Social)-Faculdade de Serviço Social, Pontifícia Universidade Católica do Rio Grande do Sul, Porto Alegre, 2007. 
DRAIBE, S. M. Brasil: o sistema de proteção social e suas transformações recentes. Santiago: CEPAL, 1993.

FAGUNDES, S. M. S. Águas da pedagogia da implicação: intercessões da educação para políticas públicas de saúde. 2006. 248f. Dissertação (Mestrado em Educação)Programa de PósGraduação em Educação, Faculdade de Educação, Universidade Federal do Rio Grande do Sul, Porto Alegre, 2006.

FARIA, C. G. O Programa de Saúde Mental na Secretaria da Saúde. Revista de Psiquiatria do Rio Grande do Sul, Porto Alegre, v. 3, n. 2, p. 91-98, 1981.

FLEURY, S. Estado sem cidadãos: seguridade social na América Latina. Rio de Janeiro: Fiocruz, 1994.

FUNDAÇÃO DE ECONOMIA E ESTATÍSTICA. A política social brasileira 1930-1964: a evolução institucional no Brasil e no Rio Grande do Sul. Porto Alegre: FEE, 1983.

GODOY, J. Psiquiatria no Rio Grande do Sul. Porto Alegre: ed. do autor, 1955.

GUIMARÃES, R.; TAVARES, R. (Org.). Saúde e sociedade no Brasil: anos 80. Rio de Janeiro: Relume-Dumará, 1994.

HOCHMAN, G. Reformas, Instituições e Políticas de Saúde no Brasil (1930-1945). Educar, Curitiba, n. 25, p. 127-141, 2005. Disponível em:

http://ojs.c3sl.ufpr.br/ojs2/index.php/educar/article/viewfile/2242/18 74>. Acesso em: 15 abr. 2006.

IAMAMOTO, M. V.; CARVALHO, R. Relações sociais e serviço social no Brasil: esboço de uma interrogação históricometodológica. 6. ed. São Paulo: Cortez; Lima: Celats, 1988.

MÉDICI, A. C. A regulação do Trabalho no Âmbito da Saúde. Ensaios FEE, Porto Alegre, v. 16, n. 1, 1995.

MERHY, E.; QUEIROZ, M. Saúde pública, rede básica e o sistema de saúde brasileiro. Cadernos de Saúde Pública, Rio de Janeiro, v. 9, n. 2, abr./jun. 1993.

NORONHA, J. C.; LEVCOVITZ, E. AIS - SUDS - SUS: os caminhos do direito à saúde. In: GUIMARÃES, R.; TAVARES, R. (Org.). Saúde e sociedade no Brasil: anos 80 . Rio de Janeiro: Relume-Dumará, 1994, p. 73-111.

PAULIN, L. F.; TURATO, E. R. Antecedentes da Reforma Psiquiátricas no Brasil: as contradições dos anos 1970. História, Ciências, Saúde-Manguinhos, Rio de Janeiro, v. 11, n. 2, maio/ago. 2004. Disponível em: <http://dx.doi.org/10.1590/S010459702004000200002>. Acesso em: 18 out. 2006.

ORGANIZAÇÃO MUNDIAL DA SAÚDE. Cuarto informe técnico. Genebra: OMS, 1955.

ORGANIZAÇÃO PAN-AMERICANA DE SAÚDE. Declaração de Caracas. $14-17$ de novembro de 1990. In: CONSELHO REGIONAL DE 
PSICOLOGIA. 6a Região. Trancar não é tratar, liberdade: o melhor remédio. 2. ed. São Paulo: CRP 6a Região, 1997.

PEREIRA, P. Necessidades humanas: subsídios à crítica dos mínimos sociais. São Paulo: Cortez, 2002.

RIO GRANDE DO SUL. Decreto n. ${ }^{\circ} 16.722$, de agosto de 1964. Cria ambulatório de Saúde Mental. Diário oficial do Estado, Porto Alegre, 8 ago. 1964.

SAES, D. Uma Interpretação Marxista da Evolução do Estado no Brasil. In: COSTA, S. (Org.). Concepções e formação do Estado brasileiro. São Paulo: Anita Garibaldi, 1999.

STANCIK, M. A. Os jecas do literato e do cientista: movimento eugênico, higienismo e racismo na primeira República. Publicatio UEPG Ciências Humanas, Linguistica, Letras e Artes, Ponta Grossa, v. 13, n. 1, p. 45-62, 2004. Disponível em: <http://www.revistas2.uepg.br/index.php/humanas/article/view/535 $>$. Acesso em: 13 abr. 2006.

TEIXEIRA, S. F. Reflexões Teóricas sobre Democracia e Reforma Sanitária. In: TEIXEIRA, S. F. (Org.). Reforma sanitária: em busca de uma teoria. São Paulo: Cortez; Rio de Janeiro: Abrasco, 1989.

TUÑON, J. F.; ABUDARA, C. Da instituição do possível à possibilidade de uma instituição. In: BERLINCK, M. T.; RODRIGUES, S. A. (Org.). Psicanálise de sintomas sociais. São Paulo: Escuta, 1988, p. 173190.

WADI, Y. M. Palácio para guardar doidos: uma história das lutas pela construção do hospital de alienados e da psiquiatria no Rio Grande do Sul. Porto Alegre: Ed. UFRGS, 2002.

\section{Endereço para correspondência}

Míriam Thais Guterres Dias

Rua Ramiro Barcelos, 2600, sala 300 B - $3^{\circ}$ andar. Bairro Santa Cecília, Porto

Alegre - RS. CEP 90035-003

Endereço eletrônico: miriam.dias@ufrgs.br

Recebido em: 24/11/2011

Reformulado em: 02/12/2012

Aceito para publicação em: 10/12/2012

Acompanhamento do processo editorial: Ana Maria Jacó Vilela

\section{Notas}

*Professora Doutora em Serviço Social; Universidade Federal do Rio Grande do Sul (UFRGS), Instituto de Psicologia - Departamento de Psicologia Social e Institucional

- Curso de Serviço Social. 